\title{
Tylenchulus semipenetrans (Nematoda: Tylenchulidae) on pomegranate in Iran
}

\author{
M. Rashidifard • E. Shokoohi • A. Hoseinipour • S. Jamali
}

Received: 4 March 2014 / Accepted: 29 December 2014 / Published online: 23 January 2015

(C) Australasian Plant Pathology Society Inc. 2015

\begin{abstract}
Tylenchulus semipenetrans was identified morphologically from root samples collected from a pomegranate plant in a garden in the Shahdad region of southeastern Iran. Molecular analysis based on the D2-D3 segment of 28S rDNA confirmed this population as T. semipenetrans. Phylogenetic analysis using the Maximum Likelihood (ML) method, places this population close to the same species from the USA, Egypt and Korea. This is the first record of T. semipenetrans on pomegranate in Iran and worldwide.
\end{abstract}

Keywords Iran · Pomegranate - Tylenchulus semipenetrans . 28S rDNA

The pomegranate, Punica granatum, is native to Iran, the largest producer of this horticultural product in the world. Although pomegranate is one of the largest export goods of Iran, there is little information about nematode parasites of pomegranate in the country. During a diagnostic visit to a pomegranate orchard in the south of Iran, we observed stunting, yellowing, wilting and slow decline in the trees. Citrus nematodes were recovered from soil and root samples.

During April-June 2013, root samples were collected from pomegranate in an orchard in Shahdad, south-eastern

\footnotetext{
M. Rashidifard $\cdot$ E. Shokoohi $(\bowtie) \cdot A$. Hoseinipour Departament of Plant Protection, College of Agriculture, Shahid Bahonar University of Kerman, Kerman, Iran e-mail: eshokoohi@uk.ac.ir

S. Jamali

Department of Plant Protection, College of Agriculture, Guilan University, Rasht, Iran
}

Iran (N. 30²5' 27.2"; E. 057 $41^{\prime}$ 50.6"). Roots were washed, blotted dry, cut in pieces and processed for nematode extraction by blender followed by centrifugal flotation (Coolen and D'Herde 1972). The roots were stained (Southey 1970) and immature and mature females observed directly on the root surfaces. Nematodes were identified and counted using an Olympus microscope $\mathrm{CH}-2$ and a Peters slide counting chamber. Specimens were fixed with hot $4 \%$ formaldehyde solution and processed to anhydrous glycerine by the method of De Grisse (1969). Measurements were taken directly using an ocular micrometer and/or a curvimeter upon drawing the corresponding organ or structure. Morphometrical characteristics and the De Man ratios (V\%, a, b, b', c, and c') were obtained from 5 second stage juveniles (J2), six adult males and 15 adult females. The molecular characterisation was based on Mehdizadeh and Shokoohi (2013). The original partial 28S (D2-D3 expansion) sequence of Tylenchulus semipenetrans is deposited in GenBank under accession number KJ577615.

Characters measured were consistent with T. semipenetrans (Inserra et al. 1988). Adult females (Figs. 1 and 2; Table 1): body swollen, $0.24-0.30 \mathrm{~mm}$ long, conical behind the vulva. Cuticle smooth and without annulation. Lateral field not observed. Cuticle 4-9 $\mu \mathrm{m}$ at mid-body. Lip region continuous with body contour, labial framework weakly sclerotised. Stylet $10-22 \mu \mathrm{m}$ with rounded knobs. Stylet knob width $2.8 \mu \mathrm{m}$; stylet knob length $1.9 \mu \mathrm{m}$. DEGO (Dorsal Esophageal Gland Orifice) 3-8 $\mu \mathrm{m}$ from the stylet knob. PVSC (Post-Vulval Section Cavity) 4-8 $\mu \mathrm{m}$; PVSL (Post-Vulval Section Length) 14-31 $\mu \mathrm{m}$; PVSW (Post-Vulval Section Width) 9-18 $\mu \mathrm{m}$. Pharyngeal procorpus cylindrical, about 2.4 times metacorpus length. Metacorpus swollen, with valve about $11 \mu \mathrm{m}$ long. Isthmus $12 \mu \mathrm{m}$ long. Basal bulb ovoid, 15-24 $\mu \mathrm{m}$ long and $14-25 \mu \mathrm{m}$ in width. Cardia conoid, surrounded by 
Fig. 1 Tylenchulus semipenetrans Cobb, 1913. a Entire male. b Entire female [Anus, Vulva and Secretory Excretory pore (SE pore) indicated by arrow]. c Anterior end of Juvenile. d Juvenile (J2). e, $\mathbf{f}, \mathbf{g}, \mathbf{i}$ posterior end of $\mathrm{J} 2$ [in $\mathbf{e}$ and f: arrow indicates genital primordium]. $\mathbf{h}$ Male posterior end

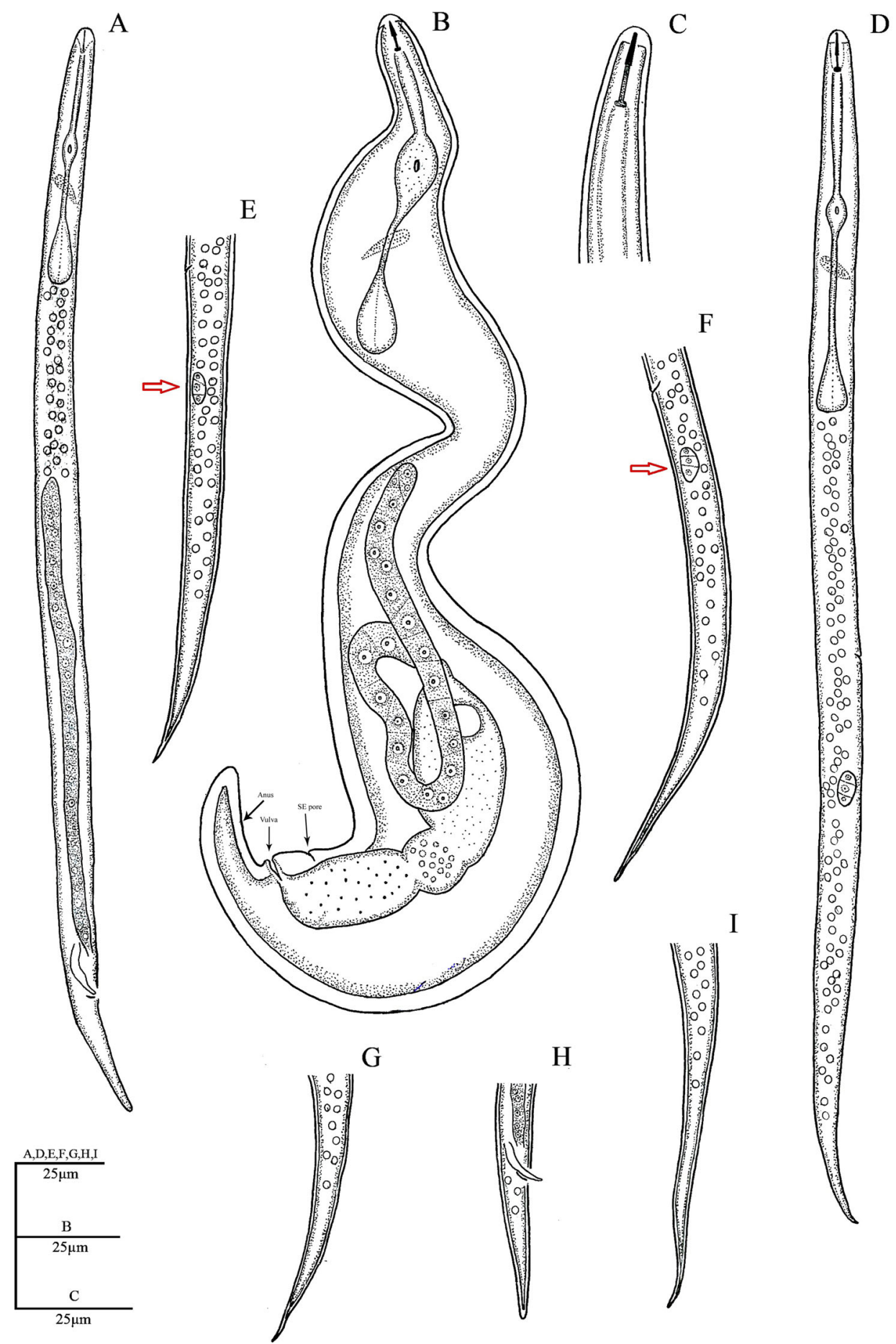

intestinal tissue. Nerve ring at isthmus level. Excretory pore at $67-78 \%$ of body length at $10-23 \mu \mathrm{m}$ to vulva. Deirid not visible. Intestine without distinct specialisations. Reproductive system monodelphic prodelphic with reflexed ovaries. Ovary long with oocytes arranged in one to two distinct rows in germinal zone. Oviducts short, not well distinguished from the adjacent uterus. Vagina with narrow lumen. Vulval opening postequatorial (around $80 \%$ from anterior end). Vulva lips weakly developed, not protruding. Anus slightly visible, but rectum not visible. Tail conical without mucro. Phasmid not visible. Male (Table 2): body "J" shaped after fixation. Cuticle smooth, lateral field not observed. Body width 10-13 $\mu \mathrm{m}$ at mid-body. Lip region continuous with body contour, labial framework weakly sclerotised. Stylet $8-11 \mu \mathrm{m}$ with rounded knobs. DEGO not visible. Pharynx tylenchoid, having pharyngeal corpus 
Fig. 2 Tylenchulus semipenetrans Cobb, 1913. On the root surface of pomegranate. $\mathbf{a}, \mathbf{b}, \mathbf{d}$ immature female. $\mathbf{c}$ mature female

Table 1 Measurements of Tylenchulus semipenetrans isolated from pomegranate

All measurements are in $\mu \mathrm{m}$ and in the form: mean \pm s.d. (range)
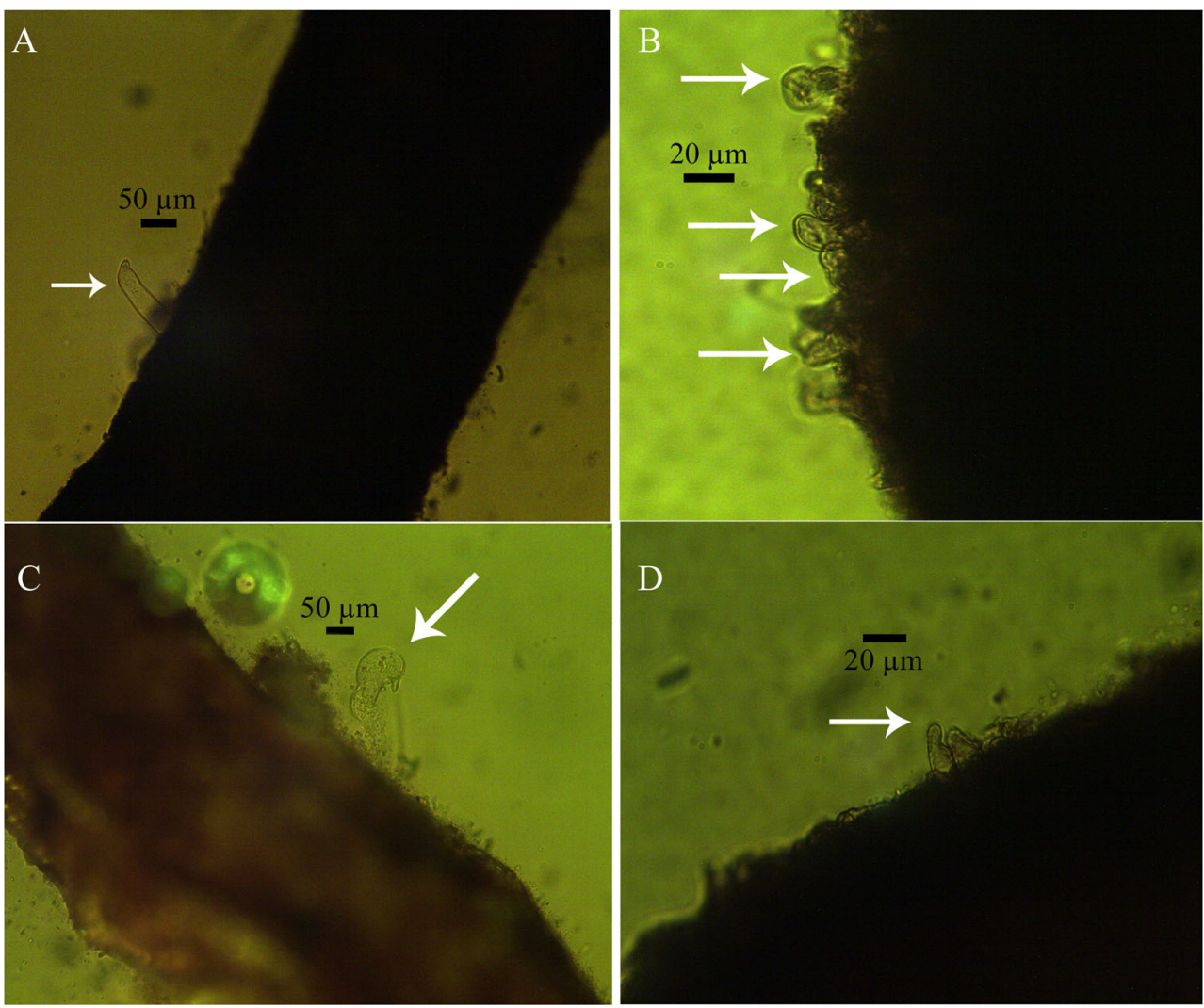

\begin{tabular}{ll}
\hline Locality & Shahdad \\
\hline Province & Kerman \\
Habitat & Pomegranate \\
$\mathrm{n}$ & 159 + \\
$\mathrm{L}$ & $276.9 \pm 28.2(245-300)$ \\
$\mathrm{a}$ & $5.6 \pm 2.2(3.6-8)$ \\
Stylet & $14.7 \pm 6.1(9.8-21.5)$ \\
DEGO & $5 \pm 2.4(3.4-7.8)$ \\
Anterior end to median bulb & $28.1 \pm 3.4(24.5-31.3)$ \\
Median bulb length & $19.1 \pm 6.2(14.7-23.5)$ \\
Median bulb width & $14.9 \pm 5.2(11.2-18.6)$ \\
Pharynx length & 135.3 \\
Basal bulb length & $19.4 \pm 3.1(14.7-23)$ \\
Basal bulb width & $18.7 \pm 3.8(13.7-24.5)$ \\
Anterior end to excretory pore & $200.8 \pm 35.5(163.4-234.1)$ \\
Excretory pore from anterior end as \% of body length & $72 \pm 5.7(66.5-78)$ \\
Vulva-excretory pore distance & $17.4 \pm 3.6(10.2-22.5)$ \\
Post-vulva section width (PVSW) & $12.9 \pm 3.1(9-18)$ \\
Post-vulva section length (PVSL) & $20.9 \pm 5.9(13.7-31.3)$ \\
Post-vulval section cavity (PVSC) & $5.4 \pm 0.3(5.1-5.7)$ \\
Swollen posterior body length & $175.2 \pm 21.2(153.6-209.7)$ \\
Swollen posterior body as \% of total body length & $58.2 \pm 4.1(55.2-62.9)$ \\
Body width at vulva & $45.3 \pm 8.6(35.2-64.6)$ \\
Body width at mid-body & $81 \pm 14.2(54.9-100)$ \\
Cuticle thickness at mid-body & $5.2 \pm 0.8(3.9-6.8)$ \\
\hline & \\
\hline
\end{tabular}


0.6-0.8 times longer than postcorpus (isthmus + basal bulb). Pharyngeal procorpus cylindrical, 2.8-3.3 times metacorpus length. Metacorpus swollen, with valve 9.3-10 $\mu \mathrm{m}$ long. Isthmus 25-30 $\mu \mathrm{m}$ long. Basal bulb ovoid, 20-26 $\mu \mathrm{m}$ long and 13-14 $\mu \mathrm{m}$ width. Cardia conoid, surrounded by intestinal tissue. Nerve ring at $68-71 \%$ of neck length, at isthmus level. Excretory pore at $51-53 \%$ of body length, $12 \mu \mathrm{m}$ to vulva. Deirid not visible. Intestine without distinct specialisations. Anus and rectum visible. Tail first conical, tapering, rounded terminus and curved ventrally. Phasmid not visible. Reproductive system monorchic, testis straight. Spicules free, curved ventrally: manubrium rounded, calamus without hump, and lamina ventrally curved. Gubernaculum simple, 4-5 $\mu \mathrm{m}$ long or about $25-27 \%$ of the spicule length. Second stage juveniles (Table 2): body almost straight after fixation. Cuticle not annulated. Lateral field not observed. Cuticle $0.6-0.8 \mu \mathrm{m}$ at mid-body. Lip region continuous with body contour, labial framework weakly sclerotised. Stylet 12-14 $\mu \mathrm{m}$ with rounded knobs. Stylet knob width 2.4-2.6 $\mu \mathrm{m}$, stylet knob length $1.5-1.8 \mu \mathrm{m}$. DEGO not visible. Pharynx tylenchoid, having pharyngeal corpus $0.4-0.7$ times longer than postcorpus (isthmus + basal bulb). Pharyngeal procorpus cylindrical, 1-2.1 times metacorpus length.
Metacorpus swollen, with valve, 10.6-11 $\mu \mathrm{m}$ long. Isthmus $28-30 \mu \mathrm{m}$ long. Basal bulb ovoid, $15-18 \mu \mathrm{m}$ long and $10-13 \mu \mathrm{m}$ width. Cardia conoid, surrounded by intestinal tissue. Nerve ring at $65-84 \%$ of neck length, at isthmus level. Excretory pore at $57-58 \%$ of body length, $20-49 \mu \mathrm{m}$ to vulva. Deirid not visible. Intestine without distinct specialisations. Genital primordium with three cells, 68-71\% from the anterior end. Anus and rectum not visible. Hyaline portion of posterior body having few small fat globules ( $<2 \mu \mathrm{m}$ width). Tail with rounded terminus. The De Man ratios obtained were: Female: $a=5.6 \pm 2.2$; male: $a=30.6 \pm$ 3.3, $b=4.7 \pm 0.7, c=8.2 \pm 0.3$; second stage juvenile: $a=23.9$ $\pm 1.1, b=3.1 \pm 0.1, c=6.9 \pm 0.7$.

The sequence lengths flanked by the two primers D2A (5"ACAAGTACCGTGAGGGAAAGTTG-3") and the reverse primer D3B (5"-TCGGAAGGAACCAGCTACTA-3") (according to Subbotin et al. 2006) of the 28S region of T. semipenetrans isolate are 747 base pairs long. The Blast test revealed that this population is 9, 11 and 13 base pairs different to the closest populations from Korea (FJ969712, 99 \% identity; FJ969715, 98 \% identity; FJ969710, $98 \%$ identity, respectively). In comparison, the nearest population studied from Egypt showed a difference of four base pairs
Table 2 Measurements of Tylenchulus semipenetrans isolated from pomegranate

All measurements are in $\mu \mathrm{m}$ and in the form: mean \pm s.d. (range)

\begin{tabular}{lll}
\hline Locality & Shahdad & \\
\hline Province & Kerman & \\
Habitat & Pomegranate & \\
$\mathrm{N}$ & $5 \mathrm{~J} 2$ & $6 \mathrm{~J}^{\top}$ \\
Body length & $304.5 \pm 13.4(282-318)$ & $325 \pm 18.5(300-345)$ \\
a & $23.9 \pm 1.1(22.5-25.2)$ & $30.6 \pm 3.3(24.4-34.4)$ \\
$\mathrm{b}$ & $3.1 \pm 0.1(2.9-3.3)$ & $4.7 \pm 0.7(4.1-6)$ \\
$\mathrm{c}$ & $6.9 \pm 0.7(5.8-7.7)$ & $8.2 \pm 0.3(7.7-8.8)$ \\
Stylet & $13.3 \pm 0.6(12.2-13.7)$ & $9.4 \pm 1(7.8-10.7)$ \\
Anterior end to median bulb & $42.9 \pm 7(34.1-51.2)$ & $37.6 \pm 1.7(35.2-40.2)$ \\
Pharynx length & $96.7 \pm 7.1(86.5-103.6)$ & $69.8 \pm 9.4(55.8-82.3)$ \\
Anterior end to hemizonid & $71.3 \pm 5.1(65.8-78)$ & $67.1 \pm 1.7(65.2-68.6)$ \\
Anterior end to excretory pore & $176.7 \pm 9.4(164.2-180.9)$ & $167.6 \pm 5.8(160.1-175.6)$ \\
Anterior end to nerve ring & $68.9 \pm 12.5(56.1-87.2)$ & $50.4 \pm 5.4(40.2-55.8)$ \\
Excretory pore to genital primordium & $30.7 \pm 13.7(19.5-48.7)$ & - \\
Anterior end to genital primordium & $210.9 \pm 7.8(200-217)$ & - \\
Genital primordium to posterior end & $120.7 \pm 4.6(117-126.8)$ & - \\
Max. body width & $12.7 \pm 0.7(12.2-13.7)$ & $10.7 \pm 1.4(9.7-13.4)$ \\
Excretory pore from anterior end as \% of body length & $59.7 \pm 4.1(52.8-63.1)$ & $20.61 \pm 2.3(17.3-23.3)$ \\
Genital primordium (\%) & $68.9 \pm 1.2(67.8-70.9)$ & - \\
Spicules & - & $17.8 \pm 1.9(14.7-19.6)$ \\
Gubernaculum & - & $4.7 \pm 0.6(3.9-5.4)$ \\
Tail & - & $38.9 \pm 2.4(35.2-42.1)$ \\
\hline & & \\
\hline
\end{tabular}


Fig. 3 The Maximum Likelihood tree inferred from known and newly sequenced Tylenchulus spp. from Iran based on $28 \mathrm{~S}$ rDNA region

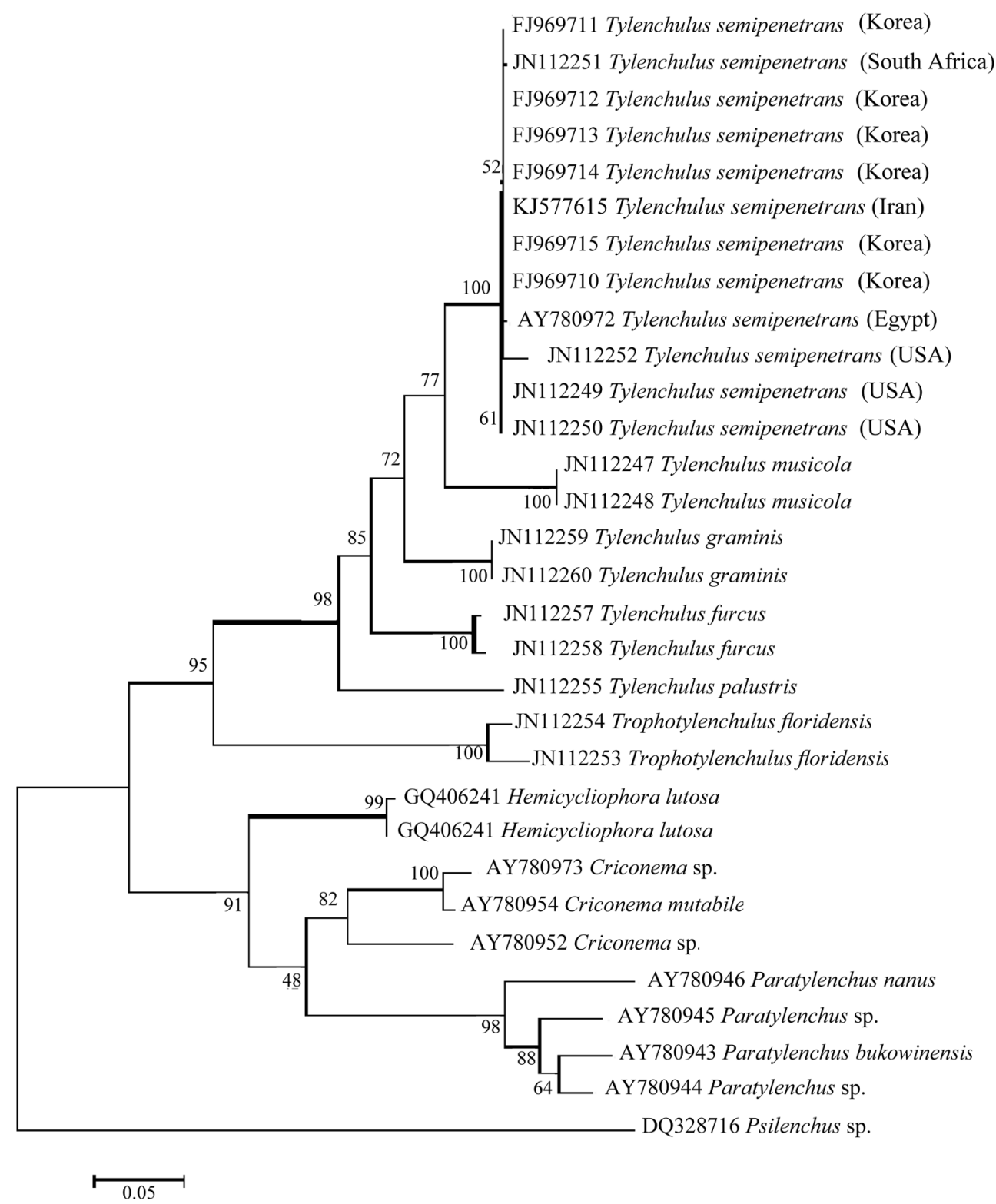

(AY780972; $99 \%$ identity). Compared with the populations from the USA (JN112249; JN112250; JN112252) 9 (99\% identity), 14 (98\% identity) and 17 (97\% identity) base pair, respectively, was shown. A ten base pair difference was shown when it was compared to a South African population (JN112251; $98 \%$ identity).

Our phylogenetic analysis using 28S rDNA, placed the Iranian T. semipenetrans population in a clade together with other T. semipenetrans populations (Fig. 3). Molecularly characterised species of $T$. semipenetrans form a monophyletic group. This result is in agreeance with previous results obtained (Van Megen et al. 2009 inferred from 18S rRNA). Three permanent microscope slides of $T$. semipenetrans (slide accession number: ES-TS1 to ES-TS3) were deposited in the Nematology laboratory collection of Shahid Bahonar University of Kerman, Iran. According to the literature, this is the first record of citrus nematode on pomegranate worldwide. Pomegranate seems to be affected by T. semipenetrans.

\section{References}

Coolen WA, D'Herde CJ (1972) A method for the quantitative extraction of nematodes from plant tissue. State Agricultural Entomology Research Station. Ghent, Belgium 
De Grisse A (1969) Redescription ou modifications de quelques techniques utililisés dans l'étude des nématodes phytoparasitaires. Meded Rijksfaculteit Landbouwetenschappen Gent 34:351-369

Inserra RN, Vovlas N, O'Bannon JH, Esser RP (1988) Tylenchulus graminis $\mathrm{n}$. $\mathrm{sp}$. and $T$. palustris $\mathrm{n}$. $\mathrm{sp}$. (Tylenchulidae) from native flora of Florida, with notes on T. semipenetrans and T. furcus. J Nematol 20:266-287

Mehdizadeh S, Shokoohi E (2013) The genera Nothacrobeles Allen \& Noffsinger, 1971 and Zeldia Thorne, 1937 (Nematoda: Rhabditida: Cephalobidae) from southern Iran, with description of $N$. abolafiai sp. n. Zootaxa 3637:325-340
Southey JF (1970) Laboratory methods for work with plant and soil nematodes. Ministry of agriculture, fisheries and food, technical bulletin 2. Her Majesty's Stationery Office, London

Subbotin SA, Sturhan D, Chizhov VN, Vovlas N, Baldwin JG (2006) Phylogenetic analysis of Tylenchida Thorne, 1949 as inferred from D2 and D3 expansion fragments of the 28S rRNA gene sequences. Nematology 8:455-474

Van Megen H, Van Den Elsen S, Holterman M, Karssen G, Mooyman P, Bongers T, Holovachov O, Bakker J, Helder J (2009) A phylogenetic tree of nematodes based on about 1200 full-length small subunit ribosomal DNA sequences. Nematology 11:927-950 